\title{
Review \\ A Review on the Importance of Microbial Biopolymers Such as Xanthan Gum to Improve Soil Properties
}

\author{
Amanda Mendonça ${ }^{1}$, Paula V. Morais ${ }^{2, *}$, Ana Cecília Pires ${ }^{2}\left(\mathbb{D}\right.$, Ana Paula Chung ${ }^{2}$ and Paulo Venda Oliveira ${ }^{3, *}$ \\ 1 Department of Mechanical Engineering, University of Coimbra, 3030-788 Coimbra, Portugal; \\ amaandamendonca@hotmail.com \\ 2 CEMMPRE, Department of Life Sciences, University of Coimbra, 3000-456 Coimbra, Portugal; \\ accp@ua.pt (A.C.P.); apchung@gmail.com (A.P.C.) \\ 3 ISISE, Department of Civil Engineering, University of Coimbra, 3030-788 Coimbra, Portugal \\ * Correspondence: pvmorais@ci.uc.pt (P.V.M.); pjvo@dec.uc.pt (P.V.O.)
}

Citation: Mendonça, A.; Morais, P.V.; Pires, A.C.; Chung, A.P.; Oliveira, P.V. A Review on the Importance of Microbial Biopolymers Such as Xanthan Gum to Improve Soil Properties. Appl. Sci. 2021, 11, 170. https://dx.doi.org/10.3390/ app11010170

Received: 27 November 2020 Accepted: 23 December 2020 Published: 27 December 2020

Publisher's Note: MDPI stays neutral with regard to jurisdictional claims in published maps and institutional affiliations.

Copyright: (C) 2020 by the authors. Licensee MDPI, Basel, Switzerland. This article is an open access article distributed under the terms and conditions of the Creative Commons Attribution (CC BY) license (https: / / creativecommons.org/ licenses/by/4.0/).

\begin{abstract}
Chemical stabilization of soils is one of the most used techniques to improve the properties of weak soils in order to allow their use in geotechnical works. Although several binders can be used for this purpose, Portland cement is still the most used binder (alone or combined with others) to stabilize soils. However, the use of Portland cement is associated with many environmental problems, so microbiological-based approaches have been explored to replace conventional methods of soil stabilization as sustainable alternatives. Thus, the use of biopolymers, produced by microorganisms, has emerged as a technical alternative for soil improvement, mainly due to soil pore-filling, which is called the bioclogging method. Many studies have been carried out in the last few years to investigate the suitability and efficiency of the soil-biopolymer interaction and consequent properties relevant to geotechnical engineering. This paper reviews some of the recent applications of the xanthan gum biopolymer to evaluate its viability and potential to improve soil properties. In fact, recent results have shown that the use of xanthan gum in soil treatment induces the partial filling of the soil voids and the generation of additional links between the soil particles, which decreases the permeability coefficient and increases the mechanical properties of the soil. Moreover, the biopolymer's economic viability was also analyzed in comparison to cement, and studies have demonstrated that xanthan gum has a strong potential, both from a technical and economical point of view, to be applied as a soil treatment.
\end{abstract}

Keywords: geotechnical engineering; microbiology; biopolymer; bioclogging; xanthan gum; soil improvement

\section{Introduction}

The construction of the current civil engineering structures, such as buildings and embankments, is only viable if the foundation soil demonstrates suitable geotechnical characteristics. In the presence of soils with poor geotechnical properties, Geotechnical Engineering uses several techniques (such as shallow and deep compaction, stone and concrete columns, the preloading technique, staged construction, shallow and deep soil stabilization with cement or other binders) to improve the soil's properties, such as strength, stiffness, erosion resistance, shear behaviour, plasticity, porosity and hydraulic conductivity, among others [1]. Since the beginning of human civilization, several different methods and materials have been used to improve the properties of soils. Especially after the Industrial Revolution, Portland cement became the most commonly used material for construction and soil treatment [2,3].

Portland cement is a material that provides many well-known benefits in the construction industry, such as the low cost, durability, high strength, and workability of the material. However, the process of production and application of the cement is linked to some environmental concerns. The $\mathrm{CO}_{2}$ emissions related to the use of cement are reported to be 
one of the world's leading causes of $\mathrm{CO}_{2}$ emissions, and represent a percentage of almost $8 \%$ of all global $\mathrm{CO}_{2}$ emissions [1,3]. In order to reduce these environmental impacts, the scientific community has been developing new, more suitable applications with reduced pollution emission [4]. Materials that are described as environmentally friendly have been developed for application using sustainable methods, namely microbial biopolymers (i.e., high molecular polysaccharides produced by microbes). These biopolymers have been introduced as an alternative to conventional techniques for soil treatment $[5,6]$. Several studies have shown a great strengthening of soil after the application of biopolymers due to direct ionic bonding with fine particles or to the formation of a continuous biopolymer matrix between coarse particles. Therefore, Geotechnical Engineering has identified various potential applications for these biopolymers to solve soil problems [2]. One of the promising applications considered is bioclogging, which promotes the production of porefilling materials in the soils through microbial means, and thus reduces the porosity and hydraulic conductivity of the soil [6]. In recent years, several studies have been published on the applicability of biopolymers, including experimental results and their analyses, but until now, there have been few cases of practical implementation [4-6].

\section{Biological Processes in Geotechnical Engineering}

Over the years, most engineers and researchers have not given adequate attention to biological processes in the soil, but the demand to satisfy society's concerns about environmental issues has forced researchers to focus on new procedures that combine the use of microorganisms in innovative soil improvement techniques [7]. As a result, the amount of research involving microbial activities to improve the soil properties required by engineering has increased and, simultaneously, so has the intention to lower rates of pollutant gas emissions when compared to the usual geotechnical practices that use Portland cement [5].

The part of Geotechnical Engineering that uses biological processes to solve geotechnical difficulties is called Biogeotechnology [2]. In other words, this is a field related to the chemical reactions achieved and measured within the soil by means of biological action [2,3]. Important factors such as the selection and proof of appropriate microorganisms for specific applications have to be considered, as do the cost-effectiveness and biosafety of the application [5]. Several studies on biotechnological engineering applications already exist, such as the use of vegetation, algae, bacteria, enzymes, and biopolymers. However, two of them, namely biocementation and bioclogging, have received special attention due to the favorable results presented by applications that modify soil's properties, in a way that is favorable to engineering, by increasing stiffness and strength and even reducing permeability $[5,8]$. Biocimentation, usually based on calcium carbonate precipitation, can be promoted by microorganisms (MICP-microbial induced calcium carbonate precipitation) or by enzymes extracted from bacteria or plants (EICP - enzyme-induced calcium carbonate precipitation). These two methodologies rely on the same chemical reactions that decompose urea into carbonate and ammonium ions. The carbonate ions combine with calcium ions to form precipitated calcium carbonate $\left(\mathrm{CaCO}_{3}\right)$ [9]. Bioclogging relies on the use of biopolymers. These bio-mediated soil improvement techniques are low-cost and require minimal extra energy, which guarantees a reduction in the carbon dioxide released and thus also contributes to reducing greenhouse gases [10].

\subsection{Application of Biopolymers in Soil Treatment}

Three main typical types of main biopolymers are considered: polynucleotides (for example, RNA and DNA), polypeptides (amino acid compounds), and polysaccharides, which have been the type most commonly applied in various engineering practices $[6,8,10]$. However, the use of biopolymers is not, in fact, an entirely new method in geotechnical engineering, since in a broad sense, organic polymers such as natural bitumen, straw, and rice have already been used in ancient civilizations and can also be classified as biopolymers. 
Studies have shown that the direct use of biopolymers in soil can have several advantages over traditional biological treatment methods. This fact can be explained because different types of biopolymers have shown a good interaction with the soil. Additionally, biopolymers have distinct properties such as good viscosity, resistance to shear degradation, and stability over wide $\mathrm{pH}$ and temperature ranges, which can promote significant strengthening effects in soils by enhancing cohesion, strength and resistance to erosion, and reducing its permeability [10].

The effect of biopolymers on the soil is related to their ability to make a stable gel matrix within the soil without damaging the local ecosystem. Moreover, they have the potential to promote vegetation growth [11], which is also beneficial in terms of stabilizing shallow soil, since it contributes to increasing soil resistance to erosion and to the satility of slope. The industrial production of biopolymers of microbial origin, such as chitosan and xanthan gum, creates biopolymers with better workability in terms of material rheology. Table 1 summarizes some characteristics of the common biopolymers used in geotechnical engineering $[6,8,12]$.

Table 1. Effect of common biopolymers on soil properties.

\begin{tabular}{|c|c|}
\hline Biopolymer & Effect \\
\hline Casein and Sodium Caseinate salt & Stabilize sand dunes [1]. \\
\hline Curdlan & Clogs the soil [2]. \\
\hline Chitosan gum & $\begin{array}{l}\text { Decreases hydraulic conductivity [11]; } \\
\text { Remediates wastewater and contaminated soil }[1,5] \text {. }\end{array}$ \\
\hline Xanthan gum & $\begin{array}{l}\text { Decreases permeability; } \\
\text { Retains water due to strong hydrogen bonding }[1,12,13] \text {. }\end{array}$ \\
\hline$\beta$-Glucan & $\begin{array}{l}\text { Increases the resistance to soil erosion and promotes the } \\
\text { growth of vegetation }[1,14] .\end{array}$ \\
\hline Gellan Gum & Improves mechanical properties $[1,4,14,15]$. \\
\hline Polyacrylamide (PAM) & Decreases soil erosion due to PAM hydrogels $[1,15]$. \\
\hline Agar Gum & Rapid gelation and increases water infiltration [16]. \\
\hline Guar Gum & $\begin{array}{l}\text { Increases mechanical properties [1,4,17-19]; } \\
\text { Reduces the collapsible potential of plastic soil [13]; } \\
\text { Decreases the hydraulic conductivity of silty sand [20]; } \\
\text { Increases the liquid limit of kaolinite clay [21]. }\end{array}$ \\
\hline
\end{tabular}

\subsection{Soil-Biopolymer Interaction}

Recent studies indicate that the effect of the use of biopolymers in soil treatment is due to the association and the balance of two main factors, the creation of additional links between the soil particles and the filling of the soil's voids (at least partially) with hydrogels. The creation of links in the soil skeleton explains the better effectiveness of this methodology in strengthening clayey soils in relation to sandy soils [1]. In fact, biopolymers have high specific surfaces with electrical charges that enable them to interact directly with the clay's minerals, and also provide firm matrices of high strength biopolymer-soil due to the electrical charges [6]. This type of link is responsible for the increase in the unconfined compressive strength and cohesion resistance observed in clay-biopolymer mixtures in relation to the results obtained with pure sands [1,12].

Although the effect of biostabilisation with biopolymers is higher in the presence of clays than in sands, the experimental results show that the impact of this methodology in sandy soils is also positive. The SEM (Scanning Electron Microscopy) image of the structure of a sand stabilized with xanthan gum (Figure 1) clearly shows that the stabilization of sandy soils with biopolymers creates a network of links between the soil particles. 


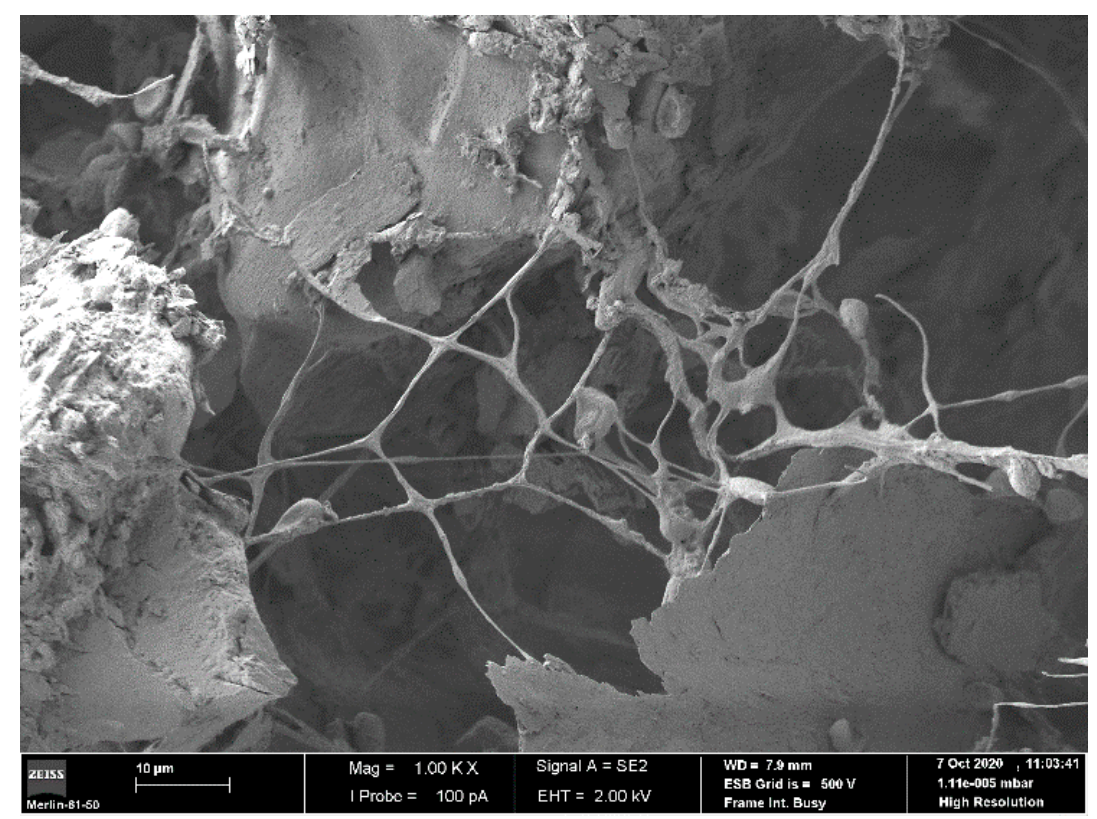

Figure 1. SEM image of the structure of a sandy soil stabilized with xanthan gum [22]. Previously, a thin layer of gold coating was deposited on the sample by sputtering. SEM tests were performed in accordance with Pansu and Gautheyrou [23].

Previous studies have demonstrated that this methodology is suitable for use in the majority of natural soils, which are composed of a mixture of coarse and fine particles (silt and clay), where there is a combination of the strength of the biopolymer-clayey-soil matrices (improvement in cohesion), and the aggregation of coarse particles (improvement in the friction angle) can be observed [11].

Taking these results into consideration, a previous in situ soil characterization is recommended to better understand its composition and to determine the most appropriate method and biopolymer to maximize the strengthening effect [12].

A second effect of the use of biopolymers in soil treatment is the formation of viscous hydrogels capable of filling the soils' pores spaces, especially in sand, which causes the bioclogging effect, which has, as a main consequence, the reducing of the hydraulic conductivity by about 3-4 orders of magnitude [13]. Therefore, biopolymers have the potential to be applied in several hydraulic purposes such as grouting, slurry walls and infiltration barriers (temporary) [14].

The amount of water is another essential factor to be considered in soil-biopolymer interaction. A study by Chang et al. [1] showed that when soils have a higher water content, the system formed by the soil and the biopolymer, whether it is a dehydrated gel or a matrix, has the ability to adsorb and transfer water to hydrogels. This induces the volumetric expansion (swelling) of the soil $[11,13]$ and a consequent increase in the distance between soil particles, leading to an increase in the soil-void ratio of the soil [24].

In fact, a recent study shows that the void ratio fundamentally increases during the first 7 days of curing time, which corresponds to the time required to hydrate the hydrogels; after that, a slight decrease in the void ratio is observed due to some dehydration of the hydrogels [24]. Therefore, some soil properties, specifically its tensile strength and stiffness, proportionally decrease with the increase in the water content and can induce a remarkable reduction in soil strength, approximately 10 times less than that which occurs in a fully saturated condition [1]. The ability of the soil-biopolymer mixtures to retain water is also confirmed by the increase in the liquid limit (LL) of the biostabilized soil with the increase in the biopolymer content [25]. 


\section{Bioclogging Technique}

The bioclogging technique is an aspect of Microbial Geotechnology used to reduce the permeability of soils and some porous rocks as a result of the accumulation of bacterial biomass and the growth of biofilms on the surface they are applied to [10].

One of the main results of the bioclogging process is the microbial production of a water-insoluble biopolymer [15]. However, to effectively adopt this microbial methodology, several factors must be considered, such as the screening and identification of suitable microorganisms to the different applications and environments. Besides the optimization of microbial activity, its biosafety, the cost-benefit ratio and the stability of the soil's properties after interaction with the biopolymer (i.e., biomodification) [2] must be evaluated. Engineers consider that bioclogging could be applied to solve engineering problems related to soils such as by diminishing the hydraulic conductivity of earthworks, reducing infiltration of the ponds and leakage in construction sites, preventing channel erosion and forming grout curtains to lower the migration of heavy metals or organic pollutants [11,12].

\subsection{Bioclogging as Solution in Geotechnical Engineering}

The integration of engineering, microbiological and ecological studies is required to implement biological methods to improve the mechanical properties of soils, and bioclogging has an important role in this solution. Bioclogging involves the use of microorganisms, especially the ones that produce polysaccharides, which results in a positive correlation between the microbial biomass produced and the stability of soil $[5,15]$.

Since the 1990s, some studies have attempted to use bioclogging tests to reduce soil permeability and diminish soil erosion [9]. Many water-insoluble polymers and gel formers of bacterial origin are produced by industry; these materials still only have limited use due to the cost involved and limited knowledge [11,14].

Consequently, laboratory tests have been carried out to identify the microbial groups that can be used for bioclogging. Ivanov et al. [2] have shown that cultures of nitrifying and oligotrophic bacteria can be used for this purpose. The culture of autotrophic nitrifying bacteria grown in sand with dissolved ammonium produces microbial polysaccharides from the ammonium and from $\mathrm{CO}_{2}$ in the air, which can reduce the hydraulic conductivity of the sand by about $10^{-4} \mathrm{~m} / \mathrm{s}$ to $10^{-6} \mathrm{~m} / \mathrm{s}$. In the case of oligotrophic heterotrophic bacteria, they were grown in the sand with a low glucose concentration and produced polysaccharides that were also capable of reducing hydraulic conductivity in the same order $[2,8]$. Some of the main different applications of bioclogging are presented in Table 2, showing their wide range, as well as some of the mechanisms and essential conditions for effective bioclogging $[16,17]$.

Table 2. Potential applications of bioclogging in Geotechnical Engineering (based on Ivanov et al. [2]).

\begin{tabular}{|c|c|c|c|}
\hline Group of Microorganisms & Bioclogging's Mechanism & Essential Conditions & $\begin{array}{c}\text { Potential Geotechnical } \\
\text { Applications }\end{array}$ \\
\hline Algae and cyanobacteria & $\begin{array}{c}\text { Formation of impermeable } \\
\text { biomass layer }\end{array}$ & $\begin{array}{l}\text { Penetration of light and } \\
\text { presence of nutrients }\end{array}$ & Reduction in water infiltration \\
\hline $\begin{array}{c}\text { Aerobic and facultative } \\
\text { anaerobic slime-production } \\
\text { bacteria }\end{array}$ & Production of slime in soil & $\begin{array}{l}\text { Presence of oxygen and } \\
\text { medium with ratio of } C: N>20\end{array}$ & $\begin{array}{l}\text { Avoidance of cover for soil } \\
\text { erosion control and slope } \\
\text { protection }\end{array}$ \\
\hline Nitrifying bacteria & Production of slime in soil & $\begin{array}{c}\text { Presence of ammonium and } \\
\text { oxygen in soil }\end{array}$ & $\begin{array}{l}\text { Reduction in drain channel } \\
\text { erosion }\end{array}$ \\
\hline Sulphate-reducing bacteria & $\begin{array}{l}\text { Production of undissolved } \\
\text { sulfides of metals }\end{array}$ & $\begin{array}{c}\text { Anaerobic conditions, } \\
\text { presence of sulfate and a } \\
\text { source of carbon in the soil }\end{array}$ & $\begin{array}{l}\text { Formation of grout curtains to } \\
\text { reduce the migration of heavy } \\
\text { metals. }\end{array}$ \\
\hline Ammonifying bacteria & $\begin{array}{l}\text { Formation of undissolved } \\
\text { metals carbonates in the soil } \\
\text { due to an increase in pH and } \\
\text { release of } \mathrm{CO}_{2}\end{array}$ & $\begin{array}{l}\text { Presence of urea and } \\
\text { dissolved metal salt }\end{array}$ & $\begin{array}{l}\text { Prevention of piping of earth } \\
\text { dams and dikes. }\end{array}$ \\
\hline
\end{tabular}


A study by Kucharski et al. [26] also claims that bioclogging can be used in industry to reduce fluid flow, improve oil recovery from reservoirs and repair cracks in concrete [16]. Bioclogging, as well as biocementation, is a technique that has several features and has the potential to grow even more due to all the advantages presented in its use. What cannot be forgotten is the fact that it is a technique directly linked to the type of biopolymer used, so it is always necessary to choose the most appropriate type for the expected target [18].

\subsection{Bioclogging Application: Benefits and Limitations}

The bioclogging method has several advantages in the field of engineering when compared to other biological soil treatment methods. Biopolymer can have a direct application since it can be produced both in-situ and ex-situ (i.e., exo-cultivation). When biopolymers are produced ex-situ, both quality and quantity can be controlled to ensure a proper bioclogging process. Apart from this, biopolymers can be produced in large quantities, react with soil particles immediately and can be applied in many different ways such as by mixing, injection or spraying, which allows their application for both temporary or rapid supporting purposes $[9,14]$. However, the greatest advantage of the bioclogging method is that it can effectively replace the more energy-demanding mechanical compaction and also the more expensive or environmentally unfriendly chemical grouting methods [15]. Bioclogging methodology also reduces carbon gas emissions, supports vegetation growth and promotes the soil stabilization, which can contribute to the farmland preservation. It also has anti-desertification effects and may be used in response to other threats to environmental conservation [16].

On the other hand, the most concerning factor of the bioclogging technique is the concentration of dissolved oxygen and destabilization of soil's properties after treatment [12]. Furthermore, the concentration of carbon, nitrogen, and metabolites such as hydrocarbons or organic acids will also largely affect the growth and activity of the clogging microorganisms in the soil. The biopolymers applied to soils are organic materials, so there must be a concern with their biodegradability over time. They are also highly sensitive to the presence of water and are subjected to cycles of wetting and drying, which can affect their durability in soil, and consequently, the strength of soils in the presence of water $[18,19]$.

Another limitation is related to the depth reached by microbial clogging in situ since the penetration of microbial cells generally only occurs to a limited depth. Therefore, the bioclogging technique can only be applied to a limited type of soils, normally sand or clay with adequate hydraulic conductivity and several other challenges are related to this use. However, the wide variety of biopolymers available and their flexibility makes bioclogging an effective option [20].

Biopolymers that are used in bioclogging have some important characteristics, such as high viscosifying power, high resistance to shear degradation, pseudoplasticity, and stability at various ranges of temperature and $\mathrm{pH}$. They are used to fill pores in granular media and, therefore, to reduce hydraulic conductivity and strengthen the material through cementation $[15,20]$. Characteristically, xanthan gum, cellulose, starch, gel gum, guar gum, agar gum and curdlan are biopolymers that show gelation properties, granting them the potential to be used in bioclogging techniques [1]. The high pseudoplasticity and the ability to increase the viscosity of the medium when mixed with it makes xanthan gum one of the best candidates to be used in soil bioclogging applications.

\section{Xanthan Gum Biopolymer}

\subsection{Xanthomonas Campestris Species}

Xanthan gum $\left(\mathrm{C}_{35} \mathrm{H}_{49} \mathrm{O}_{29}\right)$ is a polysaccharide formed by aerobic fermentation of sugar of the bacterial species Xanthomonas campestris and is commonly used as a food additive due to its characteristics as a hydrocolloid rheology modifier [20,21]. It is an anionic polysaccharide composed of D-uronic acid, D-mannose, pyruvylated mannose, 6-0-acetyl D-mannose, and 1,4-linked glucan [19]. The chemical structure is led by the linear chain 1,4-linked $\beta$-D glucose backbone with two tri-saccharide elements pairing the side chain on 
every glucose element. The other side chain is composed by a D-glucuronic acid elementlinked between two D-mannose elements $[15,19]$. The xanthan gum-produced by the type strain of the bacterial species is considered by the US Food and Drugs Administration (FDA) as an additive for industrial food; it is of great interest because it has rheological characteristics not found in other polymers [16]. Xanthomonas campestris is an aerobic and microaerophilic bacterium, so it is easily cultivated in the laboratory with an optimum growth temperature of about $25-30^{\circ} \mathrm{C}$. This species grows rapidly and produces turbidity in the medium within approximately 2 or 3 days of cultivation with an optimal $\mathrm{pH}$ between 6 and 8 [17].

\subsection{General Features}

High stability under a wide range of temperature and $\mathrm{pH}$, and also the pseudoplasticity (i.e., viscosity degradation), are important factors that make xanthan gum suitable for diverse applications [12]. This biopolymer can be mixed with both cold and hot water, but it is still highly viscous due to its ability to form a viscous hydrogel when mixed with water. This viscous hydrogel is produced through the absorption of water molecules by the hydrogen bonds that compose xanthan gum $[27,28]$.

Chang et al. [17] showed that a proportion of almost $0.5 \%$ of xanthan gum in relation to the weight of the soil is able to cause almost the same effect on the resistance to soil erosion when the equivalent of $10 \%$ of cement is used. In the specific case of Korean red-yellow soil-xanthan gum treatment, it also improved the growth of vegetation, a condition explained by its strong water adsorption during the rainy seasons and also high soil moisture retention during the dry season [29]. However, while xanthan gum or other biopolymers in the polysaccharide group have been shown to be effective even in small concentrations, what may still be a major limitation concerning its use is the issue of the price [13]. Therefore, Chang et al. [1] made a specific analysis that can prove that it is no longer valid to affirm that the cost of xanthan gum can be considered a problem. Instead, this review continued the analysis from 2015 up to 2020 and showed that, due to the increase in its use and production in large quantities, the cost of xanthan gum has reduced significantly over the last thirty years (Figure 2), that is, the cost of adding $0.5 \%$ of xanthan gum for soil treatment (i.e., $5 \mathrm{~kg}$ of xanthan gum per 1 ton of soil) has decreased from approximately 70 USD to 10 USD per ton of soil over the last three decades.

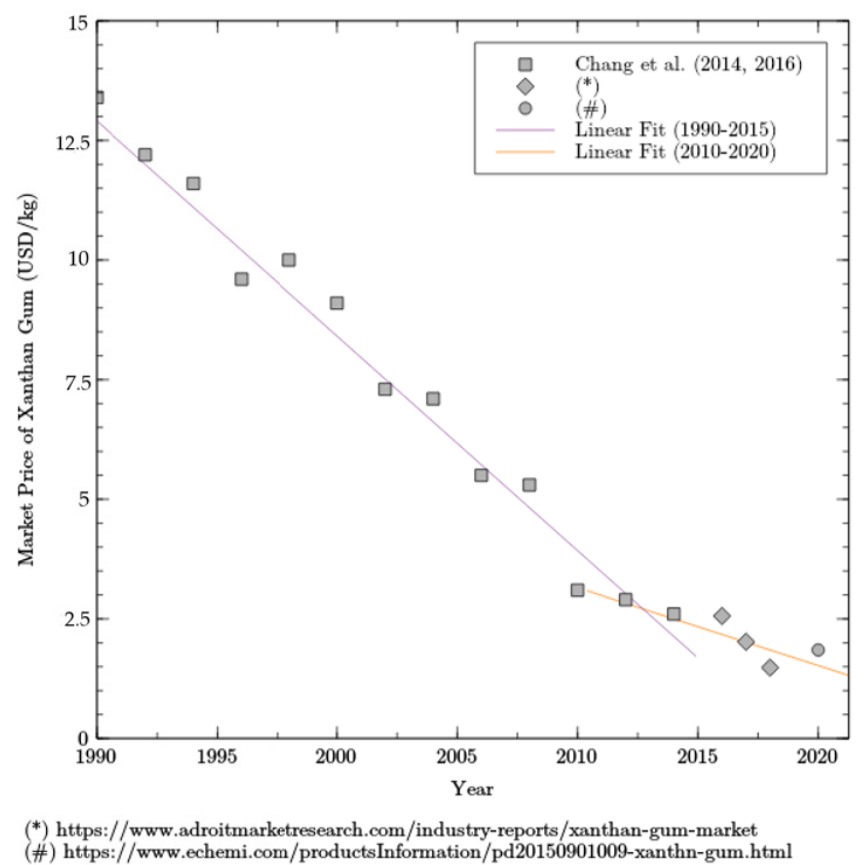

Figure 2. Decrease in the market price of the xanthan gum during the last 30 years. 
Although the use of most biopolymers currently represents a high cost for Geotechnical Engineering, further research on the subject is necessary [12]. Additionally, most of the market prices presented are intended for use in the food industry, which requires very high purity and, consequently, results in a significantly higher production cost. For geotechnical applications, such levels of purity are unnecessary and, therefore, the price of biopolymers can reasonably be expected to decrease when they are produced specifically for this purpose [12,25].

Figure 3 shows the data obtained in Jang's research [28] that compared the price of the five most common biopolymers used for soil stabilization, and it may be seen that xanthan gum and the non-biological toxic polymer polyacrylamide (PAM) cost less than $1700 € /$ ton, which is considerably cheaper than the other three polymers. For this reason, xanthan gum may definitely be considered a good option for geotechnical purposes, given the economic aspect that has only improved over the years and, in some countries, it may even represent a cheaper option than ordinary cement [12].

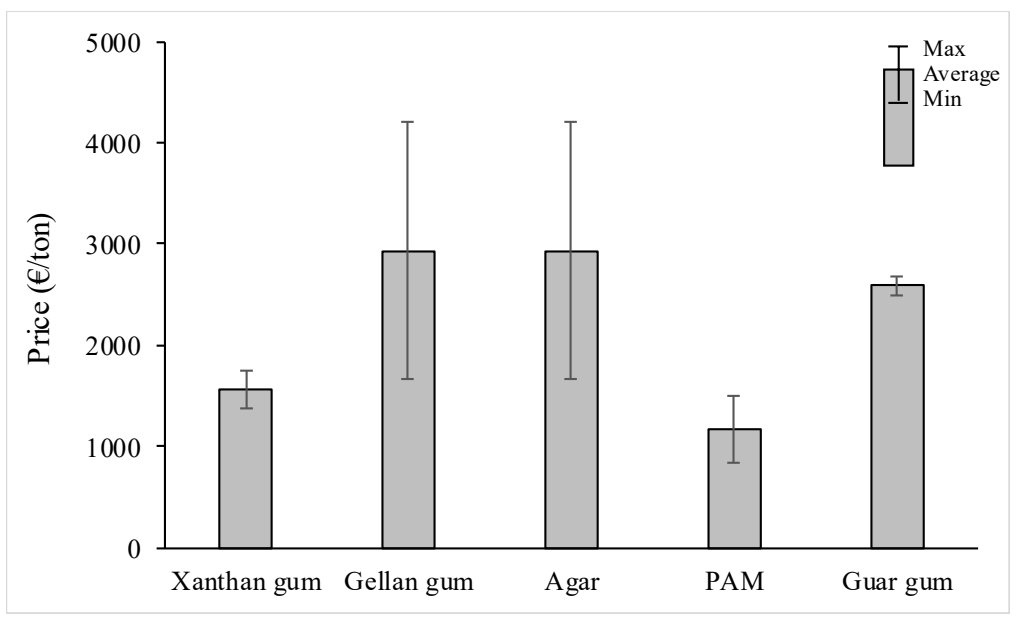

Figure 3. Prices of five common biopolymers (based on Jang [28]).

\subsection{Effects of Xanthan Gum on Soil Properties for Geotechnical Engineering}

Recent studies have shown the good performance of xanthan gum used in soils [12]. The biopolymer content, soil type and density, hydration level, mixing method and void ratio are considered the major parameters that control the use of biopolymer for shear strength and reduction in hydraulic conductivity in the field of soil improvement. Therefore, especially considering the use of xanthan gum, it also has other influencing factors, such as the presence of ions (i.e., alkali or alkali-earth metal ions) that enable the interaction (i.e., hydrogen bonding) between the inter-particle and the charged surfaces of soil that allow the formation of matrices and are similar to a hard plastic. It is expected to provide stronger hydrogen or electrostatic bonding governed by the strength of the xanthan gum between their monomers and soil particles. In addition, this biopolymer rheology increases the benefits of its use, and it has been observed that xanthan gum has better effect and workability with well-graded soils with fine particles $[15,29]$.

\subsubsection{Mechanical Properties}

A study from Lee et al. [30] concerned the strength behaviour of a sand-xanthan gum mix in three different phases of the gel: initial, dry and re-submerged. For the initial phase, the test was performed as soon as the samples were prepared; in the dried phase, the samples were in a drying room for 28 days; and the re-submerged samples were submerged in distilled water for $24 \mathrm{~h}$ before performing the tests. The study concluded that even a very small addition of xanthan gum to the sand can change the strength behaviour of this type of soil. The tests proved that increasing the xanthan gum content in the initial gel increases cohesion, but the friction angle remains constant. In the dry gel phase, both the cohesion 
angle and friction increased with the addition of more xanthan gum content due to the formation of the biofilm that occurs on the surface of particles, as well as the formation of viscous hydrogels that induces the bioclogging effect. Otherwise, the friction angles of the sand-xanthan gum mixture decreases as the xanthan gum content increases (above $1 \%$ ) in the submerged condition. This is because the interaction on the surface friction between inter-particles is reduced due to the increased pressure generated $[11,13,30]$. One of the reasons that explain the improvement in the shear strength in soil-xanthan gum mixtures is due to the presence of different chemical functional groups, such as hydroxyls and esters. Moreover, its long chain also allows additional locations in which the characteristic chemical reaction of a specific functional group can occur. As described for other polymers, the chemical bonds between the biopolymer and the soil particles are formed due to the adhesive forces that hold the soil particles on their surfaces. At microscopic scales, this effectiveness is observed through connective forces existing at the gel-particle interface, which are forces that contain and allow ionic/electrostatic or covalent bonds (i.e., chemisorption), hydrogen bonds (i.e., strong polar attraction) and Van der Waals bonds (i.e., physical absorption) [19,22,24,28].

Tests performed to determine the effect of xanthan gum content (from $0.25 \%$ to $2 \%$ ) on the modulus of elasticity of biostabilized sandy and silty soils by Ayeldeen et al. [29] show, for both soils, that the modulus of elasticity increases with the biopolymer content.

Several studies have shown that xanthan gum can be used successfully to improve the unconfined compressive strength and stiffness of sands [17,31-33], silty sands [34], clays [17,35], residual soils [36], bentonite, kaolinite [17,25,37], and soft marine clays [24], as well the undrained shear strength of mine tailing material [38]. Additionally, experimental results revealed that the most favourable xanthan gum content for soil stabilization is in the range of $1-1.5 \%$ for ambient curing and oven curing [39] and $2.5 \%$ for curing in submerged conditions [35]. Soldo et al. [40] concluded that the optimum xanthan gum content depends on the soil type and water content.

Experimental results also showed that the mechanical properties (unconfined compressive strength and stiffness) tend to improve with curing time (up to 28 days) for bentonite and kaolinite $[39,40]$, clays $[17,35]$ and sandy soils $[17,31,32,40]$. A similar time evolution was obtained for the shear strength and its strength parameters (cohesion and angle of shear strength) of clayed soils obtained from direct shear tests [35,39]. Although this tendency was confirmed for a xanthan gum-treated bentonite and kaolinite for a curing time up to 90 days [39], the results obtained from a biostabilized sand with silt indicate that the soil strength does not change considerably after a curing time of 5 days [40]. These differences in the behaviour are probably due to the fact that the bonds promoted by the xanthan gum are less exposed to the environment in a clayed soil than in pure sand, where a faster interaction of xanthan gum with water occurs [40].

As previously mentioned, the increase in the mechanical properties over time is related to dehydration of the hydrogels associated with the formation of a soil-xanthan gum matrix, which promotes the aggregation of soil particles [17,34]. Besides the positive effect on the stiffness, compressive and shear strength when using xanthan gum to stabilize soils, the results of direct tensile strength tests [41] and splitting tensile strength tests [40] carried out with air-dried specimens of two sandy soils show an increase in the tensile strength with the increase in the xanthan gum content (from 1.5 to $3 \%$ ) and with the curing time (up to 30 days). This effect is justified by the combination of higher suction and hydrogel bonding [41].

Recent research about the behaviour of xanthan gum biopolymer and sand interaction during drying indicates that this biopolymer promotes a reduced effect on shear strength when the water content is high, independently of the biopolymer content [42]. On the other hand, the continuous evaporation of the water induces a significant increase in the shear strength of the xanthan gum treated soil and this effect is higher with the increase in the xanthan gum content. Additionally, the strengthening is more significant when the drying was carried out in an oven at $40{ }^{\circ} \mathrm{C}$ than at a room temperature of $20{ }^{\circ} \mathrm{C}$. In 
fact, the latter drying conditions bring about a reduced increase in shear strength, since under these conditions the drying and the crystallization (promoted by the xanthan gum) is fundamentally superficial, while, in the inner part of the sample, the water content remains high enough to only generate weak bonds [42].

\subsubsection{Permeability}

In terms of the permeability effect, experiments by Ayeldeen et al. [29] clearly showed that xanthan gum has a remarkable effect in reducing soil permeability, in both sand and silt mixture. After 5 weeks of curing time, sand samples treated with $0.25 \%$ xanthan gum had a permeability reduction of almost $60 \%$ compared to the initial value. The same trend was observed for mixtures with silt; however, the relative amount of reduction in permeability was slightly lower in mixtures with sand.

According to Czarnes et al. [43], the reduction in permeability is a result of the crosslinking elements that form within the soil matrices and fill in the voids that can obstruct the flow of water. Another relevant factor emphasized in research studies is the curing time effect, especially related to permeability tests of xanthan gum-treated soil mixtures. Bouazza et al. [44], Dehghan et al. [45] and Cabalar et al. [31] have also stated that the permeability increases proportionally to the curing time, but this increase rate can change according to the soil type and xanthan gum concentration. This permeability rate increase is due to dehydration that causes shrinkage of the biopolymer matrices inside the gaps in the soil [25,26]. In tests by Ayeldeen et al. [29] with a sand-xanthan gum treated mixture, the permeability increased in the range of 150 to $220 \%$ between the first and the tenth week; however, for the silt-xanthan gum mixture, it was between 115 and $145 \%$ in the same period of time. For this case, the researchers state that the permeability increases more in the sand mixture instead of the silt mixture because the fine particles present in this type of soil delay the dehydration process and, consequently, the evaporation of water in the empty spaces of the soil.

Mendonça [22] compared the effectiveness of the commercial xanthan gum with a xanthan-like gum obtained directly from a strain of Stenotrophomonas sp. on the permeability of sandy soil. The results from both types of xanthan gum confirm the decrease in the permeability coefficient after biostabilisation, although this reduction is less significant with the use of the biopolymer obtained directly from the bacteria. Moreover, during 28 days of curing time the coefficient of permeability of the soil stabilized with commercial xanthan gum is approximately constant, while an increase in the permeability over time is seen with the xanthan-like strain, which may indicate some degradation of this type of gum.

Another recent study has shown that the mixture of 3\% xanthan gum with a kaolin clay also decreases the gas permeability of the biostabilized soil with pure clay by up to two orders of magnitude, which is due to pore-clogging [35]. Moreover, the decrease in the permeability caused by xanthan gum is more significant with increasing water content, since more water is available to hydrate the biopolymers and to promote the pore-clogging [35].

Although the majority of the works published show that the biostabilization of soils with xanthan gum induces a reduction in the permeability coefficient, Biju and Arnepalli's results [46] are not in line with this tendency; in fact, the mixture of xanthan gum (0.5-3\%) with sand-bentonite showed a slight increase in the permeability, which is justified by the aggregation of clay platelets, which induces wider effective flow paths [46].

Analysis of SEM images of a soil-xanthan gum mixture from different curing times [29] shows that shrinkage occurs during the time of the crosslinking of the xanthan gum within the matrices formed in the soil. This consequently increased the voids in the soil, as well as their permeability. In general, it is considered that the final stage of shrinking in the biopolymers is the transition phase between the rubber gel and the vitreous state. Through this transformation, the biopolymer gains more strength, which was also verified in the 
shear strength tests, and further, the volume of biopolymer decreased inside the empty spaces of the soil, which also generated an increase in its permeability.

\subsubsection{Stability and Durability}

Another important concern that must be addressed when using xanthan gum is related to durability. It is considered to be the case that all types of polymers, even those that are petroleum or biological-based, are biodegradable in nature. However, the rate of degradation changes according to its type of composition. So, polymers that degrade slowly or at slow rates may be considered non-biodegradable or durable [27]. Thus, the long term durability conditions for a biopolymer treated soil must be considered against its bio-decomposition, specifically under humidification and drying cycles. These conditions should be studied for each case and confirmed to provide safety recommendations concerning the use of biopolymers used in Geotechnical Engineering [30].

Xanthan gum, which is considered a very stable biopolymer, is resistant to different conditions such as thermal decomposition below $250{ }^{\circ} \mathrm{C}$, oxidation, acid/alkaline environments and high concentrations of salt [18]. Results from Muguda et al. [41] showed that the stabilization of a soil composed of sand, gravel and kaolin with $1 \%$ xanthan gum has a satisfactory durability performance against water-induced deterioration and good hygroscopic performance. Moreover, the results of slake durability carried out with xanthan gum-treated sand indicated that the resistance to disintegration upon interaction with water of the treated soil is stronger than that of the sand stabilized with Portland cement [33].

The issue of durability in the case of biopolymers applied as soil improvement materials should be evaluated in more detail on a case-by-case basis and knowledge about this subject would thus improve with more research in this area. Although it can be considered that the use of xanthan gum has numerous benefits for soil improvement, it is important to mention that the interaction between this biopolymer and the soil depends on some conditions, such as soil type, soil-biopolymer interactions or temperature and reaction with water. In general, it is expected that the physical interaction and chemical properties of xanthan gum will be better understood, in the future, so that it can be appropriately applied to the soil type and purpose according to the relevant geotechnical characteristics [22].

\subsubsection{Other Properties}

Relative to the density of the sandy soil, the results reveal an increase in density with the increment of the xanthan gum concentration [29]. The increasing density can be explained based on the nature of xanthan gum, which reduces the friction between the particles, thus inducing a better arrangement of the soil particles. This viscosity can also be expected to increase as the molecular weight of the biopolymer increases because a crystallization in its macromolecule chain is more likely. This consequently leads to an increase in the degree of crosslinking within the soil matrix.

In some works, it was observed that the optimum water content (OWC) increased with higher gum concentrations for all samples and this is due to the increase in the amount of water absorbed with the increasing concentration of the biopolymer [21,24,26].

Some experiments have shown that the use of xanthan gum also changes the liquid limit (LL) of the biostabilised soil, and this effect depends on of two opposite effects, the formation of a viscous hydrogel in the voids and the aggregation of clay particles. When the latter effect is dominant, an increase in the LL is obtained for a higher content of xanthan gum. This was obtained with a clayed silt-sand soil, montmorillonite clay [25], a soft marine soil [24] and a mine tailing [38]. For a kaolinite clay, the LL has a peak for a low content of xanthan gum (close to $0.5 \%$ ), followed by its decrease. Thus, during the first stage, the formation of the hydrogel is more significant, while after the peak, aggregation is the key factor $[25,47]$. 


\section{Conclusions and Future Research}

In this review, we have summarized the importance of the application of biopolymers in geotechnical engineering and have provided detailed examples of the applications of the xanthan gum biopolymer in different types of soil. Recent studies have shown improvement in soil strength induced by adding biopolymers and, in addition, some advantages have been noted concerning the use of xanthan gum in relation to other types of biopolymers. Through the bioclogging method, the use of xanthan gum allows the soil pores to be filled and forms a barrier capable of increasing the strength and cohesion, and reducing the permeability coefficient, of the soil. Although the use of xanthan gum has benefits for both soil improvement and stabilization, it is important to ensure that the right conditions exist for a properly controlled and efficient soil-biopolymer interaction.

In conclusion, the practical application of these studies is essential to prove the results discussed here and, for this reason, future studies should focus on tests that are able to prove that the xanthan gum-soil mixture improves the soil's properties, since xanthan gum's potential is still relatively understudied.

Author Contributions: Conceptualization, A.C.P., P.V.M. and A.P.C.; writing-original draft preparation, A.M., A.C.P. and P.V.M.; writing-review and editing, A.M., P.V.M., P.V.O. and A.P.C.; funding acquisition, P.V.M. and P.V.O. All authors have read and agreed to the published version of the manuscript.

Funding: This work was supported by the projects PTW PTDC/AAGREC/3839/2014 and POCI-010145-FEDER-031820 funded by the COMPETE2020, and by Fundação para a Ciência e Tecnologia (FCT), project PTDC/CTA-AMB/31820/2017 and FCT UIDB/00285/2020, BIORECOVER H2020 grant agreement 821096, project POCI-01-0145-FEDER-028382 and the R\&D Unit Institute for Sustainability and Innovation in Structural Engineering (ISISE), under reference UIDB/04029/2020.

Institutional Review Board Statement: Not applicable.

Informed Consent Statement: Not applicable.

Data Availability Statement: No new data were created or analyzed in this study. Data sharing is not applicable to this article.

Acknowledgments: This work had the lab technician support of J.A. Lopes, Department of Civil Engineering, University of Coimbra.

Conflicts of Interest: The authors declare no conflict of interest.

\section{References}

1. Chang, I.; Im, J.; Cho, G.-C. Introduction of microbial biopolymers in soil treatment for future environmentally friendly and sustainable geotechnical engineering. Sustainability 2016, 8, 251. [CrossRef]

2. Ivanov, V.; Chu, J. Applications of microorganisms to geotechnical engineering for bioclogging and biocementation of soil in situ. Rev. Environ. Sci. Biotechnol. 2008, 7, 139-153. [CrossRef]

3. Murphy, E.M.; Ginn, T.R. Modeling microbial processes in porous media. Hydrogeol. J. 2000, 8, 142-158. [CrossRef]

4. Basu, D.; Misra, A. Sustainability in Geotechnical Engineering. In Proceedings of the 18th International Conference on Soil Mechanics and Geotechnical Engineering, Paris, France, 2-6 September 2013. [CrossRef]

5. Narjary, B.; Aggarwal, P.; Singh, A.; Chakraborty, D.; Singh, R. Water availability in different soils in relation to hydrogel application. Geoderma 2012, 187-188, 94-101. [CrossRef]

6. Murthy, V.N.S. Geotechnical Engineering: Principles and Pratices of Soil Mechanics and Foudation Engineering; Marcel Dekker, Inc.: New York, NY, USA, 2016.

7. Baveye, P.; Vandevivere, P.; Blythe, L.H.; DeLeo, P.; Sanchez, L.D. Environmental Impact and Mechanisms of the Biological Clogging of Saturated Soils and Aquifer Materials. Crit. Rev. Environ. Sci. Technol. 2010, 28, 123-191. [CrossRef]

8. Velde, K.V.D.; Kiekens, P. Biopolymers: Overview of several properties and consequences on their applications. Polym. Test. 2002, 21, 433-442. [CrossRef]

9. Choi, S.; Chang, I.; Lee, M.; Lee, J.; Han, J.; Kwon, T. Review on geotechnical engineering properties of sands treated by microbially induced calcium carbonate precipitation (MICP) and biopolymers. Constr. Build. Mater. 2020, 246, 118415. [CrossRef]

10. Jose, A.; Carvalho, F. Starch as Source of Polymeric Materials. In Biopolymers: Biomedical and Environmental Applications; Wiley: Salem, MA, USA, 2011.

11. Khachatoorian, R.; Petrisor, I.G.; Khan, C.C.; Yen, T.F. Biopolymer plugging effect: Laboratory-pressurized pumping flow studies. J. Petroleum. Sci. Eng. 2013, 38, 13-21. [CrossRef] 
12. Smitha, S.; Sachan, A. Use of agar biopolymer to improve the shear strength behavior of sabarmati sand. Int. J. Geotech. Eng. 2016, 10, 387-400. [CrossRef]

13. Mataix-Solera, J.; Guerrero, C.; Hernandez, M.T.; Garcia-Orenes, F.; Mataix-Beneyto, J.; Gomez, I.; Escalante, B. Improving soil physical properties related to hydrological behaviour by inducing microbiological changes after organic amendments. Geophys. Res. 2005, 7, 00341. [CrossRef]

14. Chang, I.; Prasidhi, A.K.; Im, J.; Shin, H.D.; Cho, G.C. Soil treatment using microbial biopolymers for anti-desertification purposes. Geoderma 2016, 44, 253-254. [CrossRef]

15. Chang, I.; Prasidhi, A.K.; Im, J.; Cho, G.C. Soil strengthening using thermo-gelation biopolymers. Const. Build. Mat. 2015, 77, 430-438. [CrossRef]

16. Mitchell, J.K.; Santamarina, J.C. Biological considerations in geotechnical engineering. J. Geotech. Geoenviron. Eng. 2005, 131, 1222-1233. [CrossRef]

17. Chang, I.; Im, J.; Prasidhi, A.K.; Cho, G.C. Effects of Xanthan gum biopolymer on soil strengthening. Constr. Build. Mater. 2015, 74, 65-72. [CrossRef]

18. Yakimets, I.; Paes, S.S.; Wellner, N.; Smith, A.C.; Wilson, R.H.; Mitchell, J.R. Effect of Water Content on the Structural Reorganization and Elastic Properties of Biopolymer Films: A Comparative Study. Biomacromolecules 2007, 8, 1710-1722. [CrossRef]

19. Stewart, T.L.; Fogler, H.S. Biomass plug development and propagation in porous media. Biotechnol. Bioeng. 2001, 72, 353-363. [CrossRef]

20. Garcia-Ochoa, F.; Santos, V.E.; Casas, J.A.; Gomez, E. Xanthan gum: Production, recovery, and properties. Biotechnol. Adv. 2000, 18, 549-579. [CrossRef]

21. Bouazza, A.; Gates, P.W.; Ranjith, P.G. Hydraulic conductivity of biopolymer-treated silty sand. Geotechnique 2009, 59, 71-72. [CrossRef]

22. Mendonça, A.C.S. Use of Microbial Biopolymer to Decrease Soil Permeability by Bioclogging. Master's Thesis, University of Coimbra, Coimbra, Portugal, 2020.

23. Pansu, M.; Gautheyrou, J. Handbook of Soil Analysis-Mineralogical, Organic and Inorganic Methods; Springer-Verlag: Berlin, Germany, 2006.

24. Kwon, Y.M.; Chang, I.; Lee, M.; Cho, G.C. Geotechnical engineering behavior of biopolymer-treated soft marine soil. Geomech. Eng. 2019, 17, 453-464. [CrossRef]

25. Chang, I.; Kwon, Y.-M.; Im, J.; Cho, G.C. Soil consistency and interparticle characteristics of Xanthan gum biopolymer-containing soils with pore-fluid variation. Can. Geotech. J. 2019, 56, 1206-1213. [CrossRef]

26. Kucharski, E.S.; Winchester, W.; Leeming, W.A.; Cord-Ruwisch, R.; Muir, C.; Banjup, W.A.; Whiffin, V.S.; Al-Thawadi, S.; Mutlaq, J. Microbial Biocementation. International Patent Application No.PCT/AU2005/001927, 29 June 2006.

27. Krishna Leela, J.; Sharma, G. Studies on xanthan production from Xanthomonas campestris. Bioprocess. Eng. 2000, 23, 687-689. [CrossRef]

28. Jang, J. A Review of the Application of Biopolymers on Geotechnical Engineering and the Strengthening Mechanisms between Typical Biopolymers and Soils. Adv. Mater. Sci. Eng. Hindawi 2020, 2020, 1-16. [CrossRef]

29. Ayeldeen, K.M.; Abdelazim, M.N.; Mostafa, A.E.S. Evaluating the physical characteristics of biopolymer/soil mixtures. Arab. J. Geosci. 2016, 9, 371. [CrossRef]

30. Lee, S.; Chang, I.; Chung, M.K.; Kim, Y.; Kee, J. Geotechnical shear behavior of xanthan gum biopolymer treated sand from direct shear testing. Geomech. Eng. 2017, 12, 831-847. [CrossRef]

31. Cabalar, A.F.; Wiszniewski, M.; Skutnik, Z. Effects of Xanthan Gum Biopolymer on the Permeability, Odometer, Unconfined Compressive and Triaxial Shear Behavior of a Sand. Soil Mech. Found. Eng. 2017, 54, 356-361. [CrossRef]

32. Cabral, D.J.R. Stabilization of a Soil through the Use of Biopolymers: Effect of the Content and Curing Time. Master's Thesis, University of Coimbra, Coimbra, Portugal, 2020. (In Portuguese)

33. Qureshi, M.U.; Chang, I.; Al-Sadarani, K. Strength and durability characteristics of biopolymer-treated desert sand. Geomech. Eng. 2017, 12, 785-801. [CrossRef]

34. Lee, S.; Chung, M.; Park, H.M.; Song, K.-I.; Chang, I. Xanthan gum Biopolymer as Soil-Stabilization Binder for Road Construction Using Local Soil in Sri Lanka. J. Mater. Civ. Eng. 2019, 31, 06019012. [CrossRef]

35. Joga, J.R.; Varaprasad, B.J.S. Sustainable Improvement of Expansive Clays Using Xanthan Gum as a Biopolymer. Civ. Eng. J. 2019, 5, 1863-1903. [CrossRef]

36. Chang, I.; Jeon, M.; Cho, G.C. Application of microbial biopolymers as an alternative construction binder for earth buildings in underdeveloped countries. Int. J. Polym. Sci. 2015. [CrossRef]

37. Fatehi, H.; Abtahi, S.M.; Hashemolhosseini, H.; Hejazi, S.M. A novel study on using protein based biopolymers in soil strengthening. Constr. Build. Mater. 2018, 167, 813-821. [CrossRef]

38. Chen, R.; Zhang, L.; Budhu, M. Biopolymer Stabilization of Mine Tailings. J. Geotech. Geoenviron. Eng. 2013, 139, 1802-1807. [CrossRef]

39. Latifi, N.; Horpibulsuk, S.; Meehan, C.L.; Abd Majid, M.Z.; Tahir, M.M.; Mohamad, E.T. Improvement of Problematic Soils with Biopolymer-An Environmentally Friendly Soil Stabilizer. J. Mater. Civ. Eng. 2017, 29, 04016204. [CrossRef]

40. Soldo, A.; Miletić, M.; Auad, M.L. Biopolymers as a sustainable solution for the enhancement of soil mechanical properties. Sci. Rep. 2020, 10, 1-13. [CrossRef] [PubMed] 
41. Muguda, S.; Booth, S.J.; Hughes, P.N.; Augarde, C.E.; Perlot, C.; Bruno, A.W.; Gallipoli, D. Mechanical properties of biopolymerstabilised soil-based construction materials. Géotech. Lett. 2017, 7, 309-314. [CrossRef]

42. Chen, C.; Wu, L.; Perdjon, M.; Huang, X.; Peng, Y. The drying effect on xanthan gum biopolymer treated sandy soil shear strength. Constr. Build. Mater. 2019, 197, 271-279. [CrossRef]

43. Czarnes, S.; Hallett, P.D. Root and microbial-derived mucilages affect soil structure and water transport. Eur. J. Soil Sci. 2000, 51, 435-443. [CrossRef]

44. Khatami, H.; O'Kelly, B. Improving mechanical properties of sand using biopolymers. J. Geotech. Geoenviron. 2013, 139, 1402-1406. [CrossRef]

45. Dehghan, H.; Tabarsa, A.; Latifi, N.; Bagheri, Y. Use of Xanthan and guar gums in soil strengthening. Clean Technol. Environ. Policy 2019, 21, 155-165. [CrossRef]

46. Biju, M.S.; Arnepalli, D.N. Effect of biopolymers on permeability of sand-bentonite mixtures. J. Rock Mech. Geotech. Eng. 2020, 12, 1093-1102. [CrossRef]

47. Nugent, R.; Zhang, G.; Gambrell, R. Effect of exopolymers on the liquid limit of clays and its engineering implications. Transp. Res. Rec. 2010, 2101, 34-43. [CrossRef] 